\begin{tabular}{|c|c|c|}
\hline & \multirow{2}{*}{$\begin{array}{c}\text { International Journal of Current Research in } \\
\text { Biosciences and Plant Biology } \\
\text { Volume } 7 \text { • Number } 2 \text { (February-2020) • ISSN: 2349-8080 (Online) }\end{array}$} & $=$ \\
\hline & & \\
\hline PUBLISHERS & Journal homepage: $\underline{\text { www.ijcrbp.com }}$ & \\
\hline
\end{tabular}

\title{
Studies on the forced adaptation of cells of testicles and kidneys of lambs and goats to continuous growth in vitro
}

\author{
L. B. Kutumbetov and B. Sh. Myrzakhmetova* \\ Ministry of Education and Science of the, Science Committee, «Research Institute for Biological Safety Problems» \\ Gvardeiskiy village, Kordai district, Republic of Kazakhstan \\ ${ }^{*}$ Corresponding author; e-mail: ribsp@biosafety.kz
}

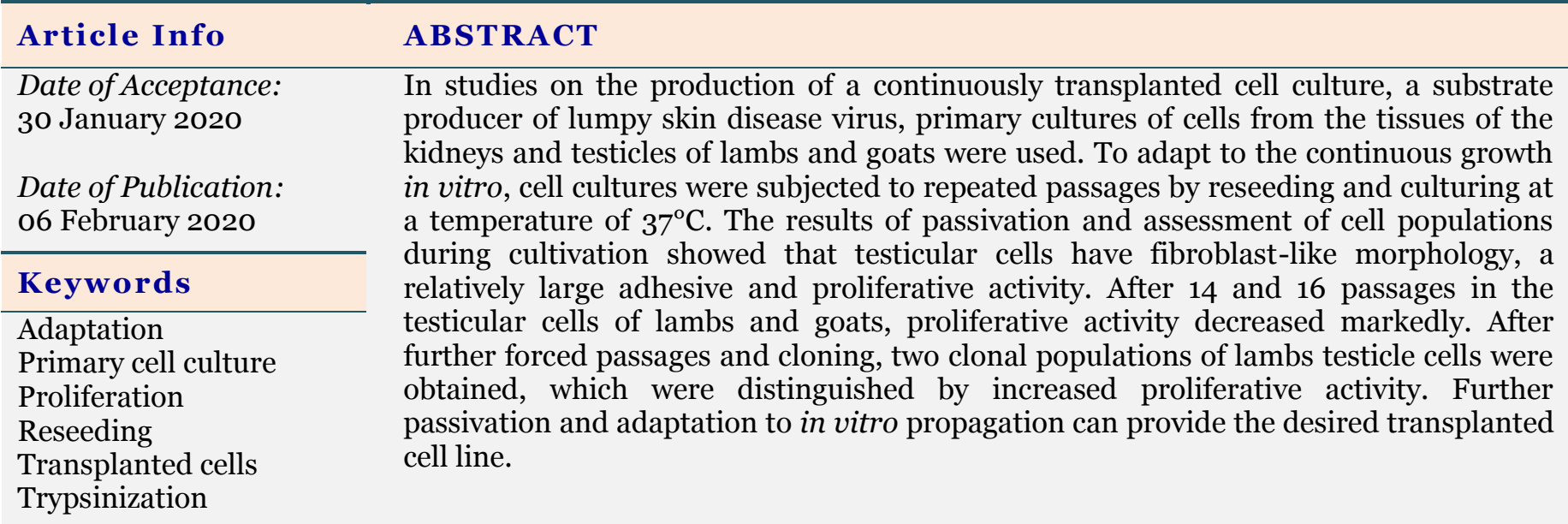

\section{Introduction}

In virological practice, in vitro reproduction of viruses uses cell cultures obtained by primary trypsinization, and cultures of transplantable cells are constantly maintained in the laboratory (Syurin, 1966; Shumilova, 2017). Each type of cell culture has its own advantages and disadvantages. Primary cell cultures are prepared from animal donor organs and are used once. For a new batch of cell culture, organ donors are again required. Since the renal cells of calves and lambs are used in the practice of reproducing the virus of lumpy skin disease, the production of viral mass is strictly related to the presence of these animal species (Syurin, 1998; Kutumbetov, 2010).

The use of calves is not technological and expensive, and the lambs are born seasonally, and therefore the production of drugs is not constant. Therefore, based on the fact that cell 
cultures prepared from the organs of the listed animal species are sensitive to the target virus, the choice of research direction for the development of transplanted cell cultures was carried out using cells prepared from the organs of lambs and goats. In addition, according to several authors who studied the biological and reproductive properties of pathogens of the genus Capripoxvirus, which also includes the virus of lumpy skin disease, indicate that these viruses replicate well in cell cultures from the kidneys and testicles of lambs and goats (Maykhin, 2003; Chihota et al., 2001).

The transferred cell cultures, unlike the primary ones, are constantly maintained in the laboratory and, if necessary, can be subjected to standardization according to the requirements of the target technology. The production of such cell cultures does not depend on the availability of donors and the season of their appearance. However, many transplantable cell cultures can pose a threat to the recipient's health as the most potential carcinogens. Therefore, when choosing transplantable cell cultures necessary for the production of parenteral preparations, it is necessary to subject them to rigorous testing for negative parameters and to exclude such properties. Basically, cell cultures obtained from tumor formations, such as HeLa, HEP-2, etc., possess such properties (Tuppurainen et al., 2013; Chihota et al., 2003).

In the practice of manufacturing veterinary and medical preparations, including live vaccines, individual cell lines are used, which include BHK21 and its various clonal variants, Vero (OIE, 2012; Tuppurainen et al., 2005). Many inactivated veterinary vaccines are prepared using a variety of transplantable cell cultures.

In cell biotechnology, in addition to primary and transplanted lines, strain cultures of cells are also used that are guaranteed not to have carcinogenic properties. In such cell cultures, a diploid set of chromosomes is preserved and possess the initial properties of primary cell cultures. Populations of these cell cultures, as well as transplanted ones, are supported by passivation and prolonged cryopreservation. Therefore, in the production technology of biological preparations, especially live vaccines, strain cell cultures are the most acceptable and technologically advanced. Based on the above possibilities of cell biotechnology, the aim of this work was to adapt, using passages, primary cell cultures obtained from testicles and kidneys of lambs and goats to continuous proliferation in vitro to obtain a transplantable cell culture with strain cell properties.

\section{Materials and methods}

In the preparation of primary cell cultures, testicle and kidney donors were lambs and goats 1-3 months old. Testicles were obtained by aseptic removal of them from the body of a donor animal by a surgical method. Animals, after taking testicles, were kept indoors until recovery.

Testicles were transported in a Hanks solution with antibiotics and in the laboratory they were mechanically cleaned of connective tissues and then trypsinized in a solution of $0.25 \%$ trypsin. Before trypsinization, the testicular tissue was cut into small, homogeneous pieces measuring 50-60 $\mathrm{mm}^{3}$ (approximately 3-4×3-4×3-4 mm).

Trypsinization was carried out according to the method described by Syurin (1966). The action of trypsin was neutralized by the blood serum of cattle used in the composition of the nutrient medium for growing cells. Cells were seeded at concentrations of $100-200 \times 10^{3}$ cells $/ \mathrm{cm}^{3}$. As a growth medium, a nutrient medium according to the prescription Eagle with a content of $10 \%$ serum of cattle was used. To regulate the cell growth rate in the nutrient medium, the concentration of blood serum was changed.

Renal cells were obtained from the kidneys of lambs and goats after their slaughter with complete bleeding. Organs were delivered to the laboratory and subjected to trypsinization, as well as plated in culture vessels, as well as tissues and testicle cells.

The cell concentration in the culture suspension was counted in a Goryaev chamber (Syurin, 1966). Cells were cultured at $37^{\circ} \mathrm{C}$ for the entire time observed. In the process of cell growth, daily data were recorded on the adhesion and morphology of cells, as well as their growth (proliferative activity) on the growth surface. 
To establish adhesive activity 24, 48, 72 hours after plating, a sample was taken from the contents of the vessels with the seeded cell suspension and the floating cells were counted. Then, the difference between the number of seeded and free cells was determined. The resulting difference was taken for the number of adherent cells from the number of seeded. Cell adhesion was assessed per day by attachment of at least 50\% of the cells seeded after trypsinization.

To determine proliferative activity, the number of adherent cells was first established, then, after the formation of a complete monolayer or 72 hours after seeding, the total number of cells present on the growth surface was determined. The digital value of the ratio of the total number of cells to the number of adherents was taken as the index of their proliferative activity. Cell morphology was studied and evaluated visually by microscopy of a monolayer of cell culture.

To adapt to continuous in vitro growth after the formation of a complete monolayer, the cell culture was reseeded, i.e. subculture. For this, the cells in the monolayer were dispersed with trypsin solution and the contents were subcultured in 2 or 3 or 4 mattresses, and in cases when the number of cells in the mattress was limited, they were subcultured only in the "own" mattress. After receiving the subculture, the trypsinization process was repeated and the next generation of cell culture was obtained. At each passage, morphology, adhesive and proliferative activity of cell cultures were evaluated. At passage 20, part of the cell population was subjected to cryopreservation at a temperature of minus $196^{\circ} \mathrm{C}$, and clones were isolated from the rest of the population, which were propagated separately, studying their morpho-functional properties.

To obtain clone cells, a suspension of cells obtained by treatment with a $0.25 \%$ trypsin solution and thoroughly mixing in a needle culture medium was diluted to a concentration of not more than 10 cells / $\mathrm{cm}^{3}$ and sown in mattresses. The cell suspension in the mattresses was kept for $24 \mathrm{~h}$ at $37^{\circ} \mathrm{C}$, then the nutrient medium was removed, the inner surface of the mattress was washed in 3 shifts with Hanks solution and introduced into a fresh nutrient medium. The adhesion of seeded cells was monitored by microscopy and single cell attachment sites were noted from the outer surface of the mattress. Single cells adhered to the inner surface of the mattress were monitored daily until they spread and small colonies formed.

Cell colonies or single cells were peeled off from the adhesion surface by mechanical scraping using a sterile Pasteur pipette. Then this pipette was sealed on both sides above the burner flame. Pipettes with single cells and their colony, together with a nutrient medium containing $15 \%$ fetal blood serum of cattle, were kept at a temperature of $37^{\circ} \mathrm{C}$ for 7-10 days. At the end of this period, the contents of each pipette were transferred to Pavitsky vials, into which 4-5 $\mathrm{cm}^{3}$ of Eagle's medium was added, containing 10\% fetal bovine serum. After 24 and daily, the contents of the vials were subsequently microscopic and the morpho-functional state of the clone cells was monitored. Assessment of the purity of the cell culture from extraneous microbiological contaminants was carried out every 5-10 passages in accordance with the requirements of GOST 28085.

\section{Results}

To obtain standard results, all obtained cell cultures were grown in 1.5-liter flat flask using the same nutrient medium and temperature.

The testicular cells of lambs and goats in morphology were similar and characterized by fibroblast-like (Figs. $1 \mathrm{~A}$ and $2 \mathrm{~B}$ ), and the kidney cells of both animal species were morphologically epithelial (Figs. $2 \mathrm{~A}$ and $2 \mathrm{~B}$ ).

The population of cells obtained by primary trypsinization, when seeding in flask, did not adhere completely. During the first and second days, part of the cells from the seeded pool was attached to the inner surface of the flask, and the remaining part floated in suspension. Adhesive cells in the first few hours had a round shape, then after 12-24 hours they spread out, taking polygonal (renal cells) and elongated (testicular cells) shapes and underwent proliferation. In the first two days, up to $50 \%$ of the seeded cells were attached to the glass surface, which then, as they proliferated, formed a monolayer for 48-72 hours. 


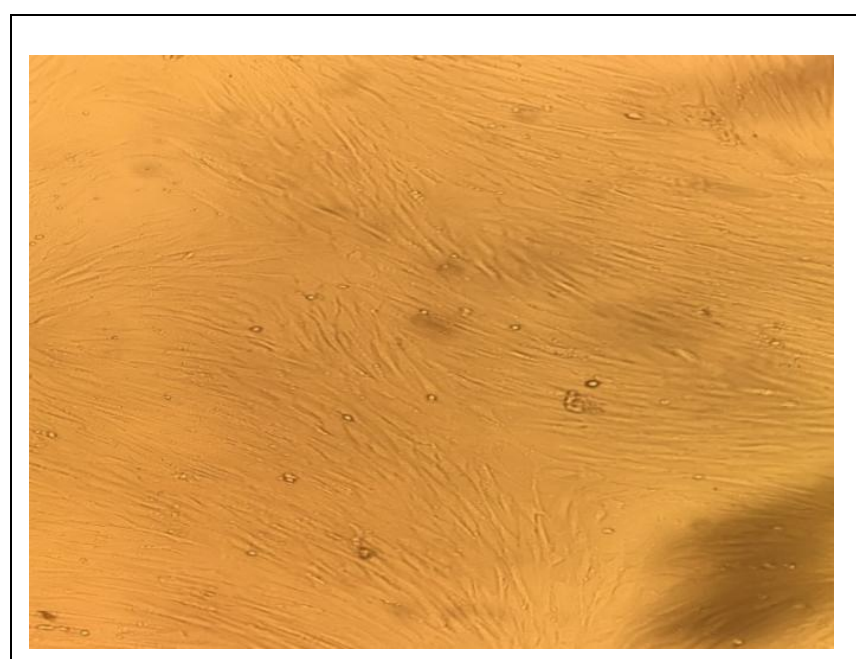

Fig. 1(A): Monolayer culture of lamb testicle cells.

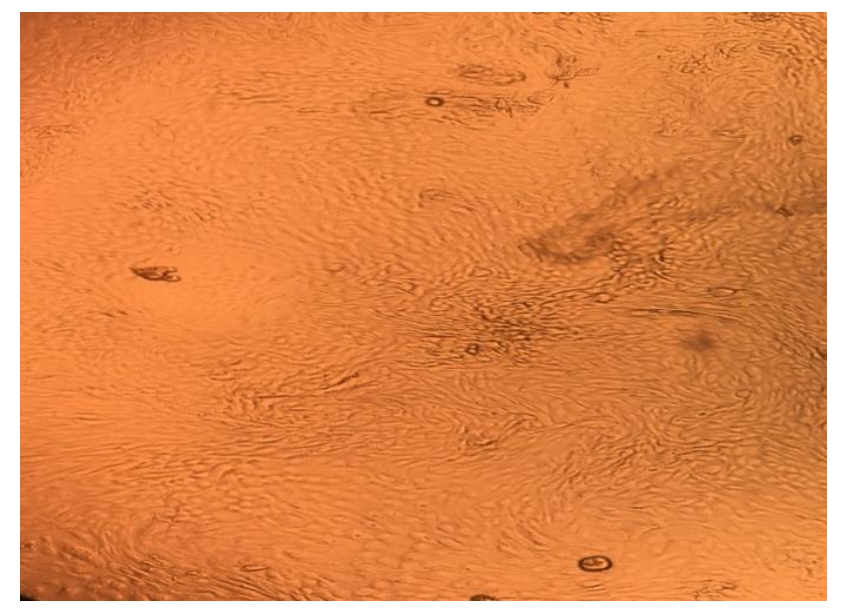

Fig. 1(B): Monolayer culture of goat testicle cells.

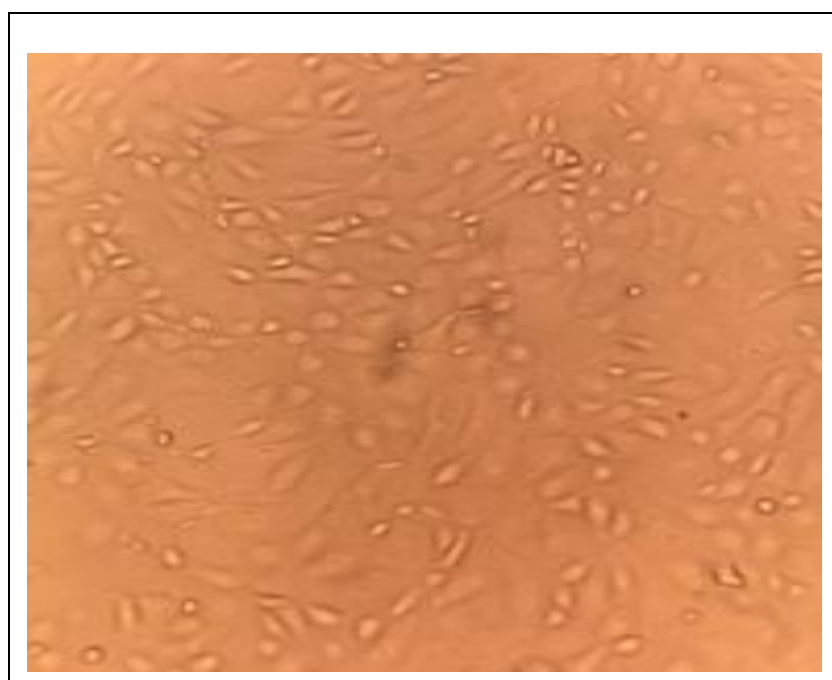

Fig. 2(A): Monolayer culture of lamb kidney cells.

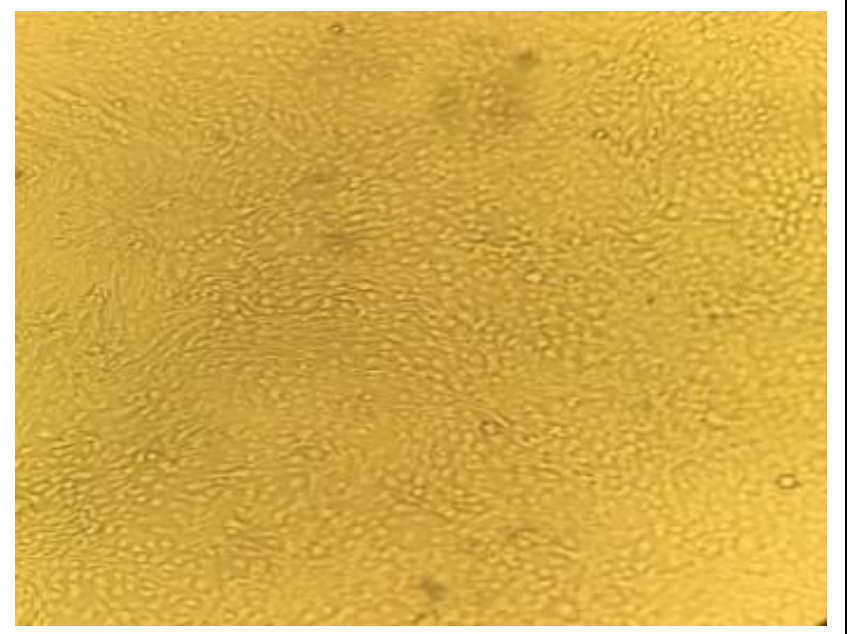

Fig. 2(B): Monolayer culture of goat kidney cells.
The proliferative activity of fibroblast-like cells was comparatively higher than that of epithelial-like cells. The results of the assessment of adhesive and proliferative activity, as well as the characteristics of cell morphology by passages are shown in Table 1.

As can be seen from the data in Table 1, in order to obtain transplanted cells with testicular cells of lambs and goat, 21 and 17 passages were performed, respectively, and with cells from kidneys of lambs and goat, 12 and 9, respectively.
During the passage periods, the adhesive properties of all 4 types of cell cultures have not changed and at least $50 \%$ of the testicular cells of lambs and goat were attached to the surface of the flask glass in 1-2 days, and the same number of kidney cells in these animals in 2-3 days. The proliferation index in the first passages was relatively higher in the culture of cells prepared from cells of lambs testicles, which was 3 , and similar goat cells had a slightly lower index, which was 2.5. In cell cultures prepared from the kidneys of lambs and goat, the proliferation index was low and equal in both cell cultures 2. 
During the passages of testicular cells of lambs, starting from passage 16 , the proliferation index decreased, and up to passage 19 it amounted to 2, and at 20 and 21 passages, cell growth slowed down even more and the multiplication rate did not exceed 1.5.

Table 1. The dynamics of morphological and functional indicators of passage cell cultures.

\begin{tabular}{|c|c|c|c|c|c|c|c|c|c|c|c|c|}
\hline \multirow{3}{*}{$\begin{array}{l}\text { Level } \\
\text { passage }\end{array}$} & \multicolumn{12}{|c|}{ Morphological and functional indicators of cell cultures } \\
\hline & \multicolumn{4}{|c|}{ Adhesion, 5o\% / day } & \multicolumn{4}{|c|}{ Proliferation, index, } & \multicolumn{4}{|c|}{ Morphology, form } \\
\hline & $\mathbf{L T}$ & GT & LK & GK & $\mathbf{L T}$ & GT & LK & GK & $\mathbf{L T}$ & GT & LK & GK \\
\hline 1 & $1-2$ & $1-2$ & $2-3$ & $2-3$ & 3 & 2.5 & 2 & 2 & FL & FL & EL & EL \\
\hline 2 & $1-2$ & $1-2$ & $2-3$ & $2-3$ & 3 & 2.5 & 2 & 2 & FL & FL & EL & EL \\
\hline 3 & $1-2$ & $1-2$ & $2-3$ & $2-3$ & 3 & 2.5 & 2 & 2 & FL & FL & EL & EL \\
\hline 4 & $1-2$ & $1-2$ & $2-3$ & $2-3$ & 3 & 2.5 & 2 & 2 & FL & FL & $\mathrm{EL}$ & EL \\
\hline 5 & $1-2$ & $1-2$ & $2-3$ & $2-3$ & 3 & 2.5 & 2 & 2 & FL & FL & EL & EL \\
\hline 6 & $1-2$ & $1-2$ & $2-3$ & $2-3$ & 3 & 2.5 & 2 & 2 & FL & FL & EL & EL \\
\hline 7 & $1-2$ & $1-2$ & $2-3$ & $2-3$ & 3 & 2.5 & 2 & 2 & FL & FL & EL & EL \\
\hline 8 & $1-2$ & $1-2$ & $2-3$ & $2-3$ & 3 & 2.5 & 2 & 2 & FL & FL & EL & EL \\
\hline 9 & $1-2$ & $1-2$ & $2-3$ & $2-3$ & 3 & 2.5 & 2 & 2 & FL & FL & EL & EL \\
\hline 10 & $1-2$ & $1-2$ & $2-3$ & - & 3 & 2.5 & 2 & - & FL & FL & EL & - \\
\hline 11 & $1-2$ & $1-2$ & $2-3$ & - & 3 & 2.5 & 2 & - & FL & FL & EL & - \\
\hline 12 & $1-2$ & $1-2$ & $2-3$ & - & 3 & 2.5 & 2 & - & FL & FL & EL & - \\
\hline 13 & $1-2$ & $1-2$ & - & - & 3 & 2.5 & - & - & FL & FL & - & - \\
\hline 14 & $1-2$ & $1-2$ & - & - & 3 & 1.5 & - & - & FL & FL & - & - \\
\hline 15 & $1-2$ & $1-2$ & - & - & 3 & 1.5 & - & - & FL & FL & - & - \\
\hline 16 & $1-2$ & $1-2$ & - & - & 2 & 1.5 & - & - & FL & FL & - & - \\
\hline 17 & $1-2$ & $1-2$ & - & - & 2 & 1.5 & - & - & FL & FL & - & - \\
\hline 18 & $1-2$ & - & - & - & 2 & - & - & - & FL & - & - & - \\
\hline 19 & $1-2$ & - & - & - & 2 & - & - & - & FL & - & - & - \\
\hline 20 & $1-2$ & - & - & - & 1.5 & - & - & - & FL & - & - & - \\
\hline 21 & $1-2$ & - & - & - & 1.5 & - & - & - & FL & - & - & - \\
\hline
\end{tabular}

Note: 1 FL - fibroblast-like; 2 EL - epithelial-like; 3 «-» - passages have not yet been held.

In cells of a similar organ of goats, proliferative activity did not noticeably change until passage 13, and in the next four their growth slowed down, and the proliferation index decreased from 2.5 to 1.5 . In the cells of the kidneys of lambs and goat during the 12 and 9 passages, respectively, the proliferation index was low and remained unchanged, which was constantly 2. Throughout all the passages, the morphological structure of the cells did not change and the testicular ones were fibroblast-like, and the kidney ones were epithelial-like.
The results of forced adaptation of cells to continuous growth outside the body show that, starting from 14-16 passages, cells of the testicular tissue of lambs and goats begin to experience functional changes that affect their proliferative activity by a decrease in the index. Probable further changes in the morphological and functional characteristics of cell cultures are expected in the following passages, to establish which and to obtain a population of single cells adapted for continuous growth in vitro, they were cloned after passage 21 . 
In total, 7 clone cells were obtained by separate cultivation of individual cells and a population (colonies from one cell) of testicular tissue cells of lambs in microtubules and Pavitsky bottles (Fig. 3). The first generation of clone cells, which in general was 22 passages for them, occurred in microtubules. Then the cell population, which appeared as a result of the multiplication of one cell, was transferred to Pavitsky's bottles and cultured until the formation of focal cell colonies of the next 23 passage level. At this passage level, out of 7 clones, only 4 clones formed visible cell colonies in the vial. Therefore, subsequent adaptation passages were performed with cells of these clones.

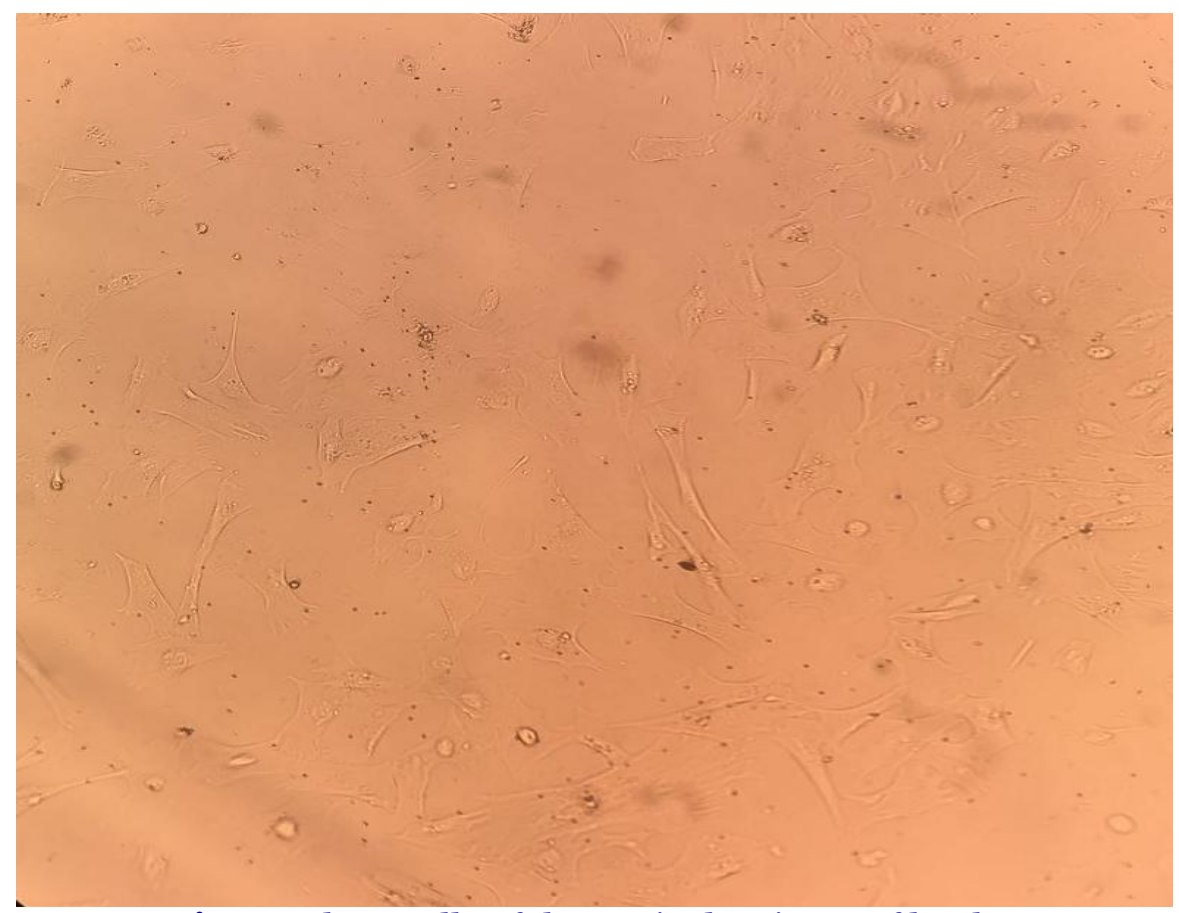

Fig. 3: Clone cells of the testicular tissue of lambs.

The results of breeding cultivation and evaluation of their morphological and functional indicators for the passages are shown in Table 2.

Table 2. Morphological and functional indicators of clones of passage cells of testicles of lambs.

\begin{tabular}{|c|c|c|c|c|c|c|c|c|c|c|c|c|}
\hline \multirow{4}{*}{$\begin{array}{l}\text { Level } \\
\text { passage }\end{array}$} & \multicolumn{12}{|c|}{ Morphological and functional indicators of clones of cells of testicles of lambs } \\
\hline & \multicolumn{4}{|c|}{ Adhesion, 50\% / day } & \multicolumn{4}{|c|}{ Proliferation, index } & \multicolumn{4}{|c|}{ Morphology, form } \\
\hline & \multicolumn{4}{|c|}{ Clone designations } & \multicolumn{4}{|c|}{ Clone designations } & \multicolumn{4}{|c|}{ Clone designations } \\
\hline & LT1 & LT2 & LT 3 & LT 4 & LT 1 & LT 2 & LT 3 & LT 4 & LT 1 & LT 2 & LT 3 & LT 4 \\
\hline 24 & 2 & 1 & 1 & 2 & 1 & 2 & 2 & 1.5 & FL & FL & FL & FL \\
\hline $25-29$ & $2-3$ & 1 & 1 & 2 & 1 & 2 & 2 & 1 & FL & FL & FL & FL \\
\hline $30-32$ & - & 1 & 1 & - & - & 3 & 2.5 & - & - & FL & FL & - \\
\hline
\end{tabular}

As can be seen from the data in Table 2, the clone cell populations numbered LT1 and LT 4 up to passage 29 had low adhesive activity and from the 3oth passage stopped attaching to the surface of the vessel glass. At the same time, the clone cell populations numbered LT2 and LT3 had good adhesive activity and adhered to the glass surface during the first day after reseeding. At the same time, it was noted that in the population of cells of the LT A2 clone, approximately 90\% undergo adhesion, and $70 \%$ of the LT $3 \mathrm{~A}$ clone. Their proliferative activity index from 24 to 30 passage 
consistently equaled two, and in the last 2-3 passages, this index increased to 2.5 in clone LT3 and up to 3 in clone LT2. Despite the changes in the adhesive and proliferative activity of the clones in the last passages, their morphological characteristics remain unchanged.

\section{Discussion}

As a result of the studies, it was found that in primary trypsinized cells of the kidneys and testicles of both lambs and goat, the ability to adhere to the cultivated surface of the flask is uneven. Since part of the cell population during the first 24 hours is attached to the surface of the flask, and the rest remains in suspension. But these cells, when transferred to another vessel, attach to the glass, but not completely, as well as during the initial seeding. Obtaining subcultures of cells from the primary by reseeding and analysis of their adhesion showed that with passages, the adhesive activity of the transplanted cells increases and, after 5-7 passages, at least $80 \%$ of the monolayer transplanted cells are attached to the glass surface. It is also possible that the population of adhesive cells increases due to the selection of such units during the passage, in which only adhesive remains, and weakly adhesive or non-adhesive are removed from the flask when the nutrient medium is replaced with fresh one, which is carried out every 3-4 days. From the above data, it can be concluded that in the process of passage by passages, the composition of the cell culture undergoes natural selection, being purified from weakly adhesive and non-adhesive cell populations. In our studies, all 4 types of cell cultures underwent such a selection process in our studies and their adhesion indicators stabilized after 3-5 passages.

The results of monitoring the proliferative activity of cell cultures showed that in testicular cells this indicator remained stable up to 13 (GT) and 15 (LT) passages. After the indicated number of generations, the proliferative activity of these cell cultures decreased from 3 to 2 (LT) and from 2.5 to 1.5 (GT), indicating the depletion of the physiological capabilities of the cells that are inherent in the body of the animal donor. At the stage of reducing proliferative activity, 5 cells were prepared from LT cell culture prepared in 7 flask. Cells were subjected to vacuolization and acquired granularity in the cytoplasm. By 20-21 passages in the cell culture of LT, the index of growth activity decreased to 1.5 .

In the future, in order to isolate individual cells capable of relatively active proliferation, a cloning of a population of testicular lambs was carried out. The results of the cultivation of clonal cells showed that among them there are two cell populations that have acquired the ability to proliferate with an index equal to the proliferation rate of the primary cells of the lambs testicles. These cell clones after 30 passages had a proliferative index of 2.5-3, i.e. their growth activity doubled. The obtained tendency to increase proliferative activity indicates that genetic shifts have occurred in the populations of these cells that encode the possibility of active growth.

\section{Conclusion}

Thus, the obtained data indicate that with repeated sequential passaging, the cultures of cells prepared from the testicular tissue of lambs change the adhesive and proliferative properties. At first, these changes are characterized by stabilization of adhesion and proliferation, then through certain passages, with stable adhesion, their proliferative activity decreases. Forced further passage with the cloning of individual cells makes it possible to obtain populations of cells capable of reactivating their proliferative properties. In cell cultures prepared from the kidneys of lambs, testicles and kidneys of goat, due to the small number of passages carried out, no noticeable changes in morphological and functional indicators were noted. To obtain a producer substrate capable of continuous growth in vitro and to produce the virus of lumpy skin disease, it is necessary to continue passaging the cell culture from the lambs testicles.

\section{Conflict of interest statement}

Authors declare that they have no conflict of interest.

\section{References}

Chihota, C. M., Rennie, L. F., Kitching, R. P., Mellor, P. S., 2001. Mechanical transmission of lumpy skin disease virus by Aedes aegypti 
(Diptera: Culicidae). Epidemiol. Infect. 126, 317-321.

Chihota, C. M., Rennie, L. F., Kitching, R. P., Mellor, P. S., 2003. Attempted mechanical transmission of lumpy skin disease virus by biting insects. Med. Vet. Entomol. 17, 294300.

Kutumbetov, L. B., 210. Technological basis for the manufacture of vaccines against sheep pox, smallpox goats and smallpox birds [Cultivation of animal pox viruses and birds]: dis ... dr. vet sciences: 16.00.03: it is protected 26.08.10: utv. 16.06.11 / Kutumbetov L.B. - A., 2010. 340p.

Maykhin, K. T., 2003. The technology of making a vaccine against sheep pox from an attenuated KazNIVI strain using a transplantable cell culture [Maintaining a substrate for the reproduction of sheep pox viruses]: dis ... kand. vet sciences: 16.00.03: it is protected 12.08.03: utv. 09.06.04 / Maykhin K.T. - A., 2003. - 97p.

OIE, 2012. Manual of Diagnostic Tests and Vaccines for Terrestrial Animals, Paris. $7^{\text {th }}$ Edn.
Vol. 1. Chap. 2.4.14. pp.762-774.

Syurin, V. N., 1966. Guidelines for Veterinary Virology [Cultivation of animal tissue cells]. M. Kolos, 680p.

Shumilova, I. N., 2017. Laboratory practice [Cultivation of bovine nodular dermatitis virus in transplantable cell culture lines] / S.V. Kononov, B.L. Manin, N.V. Koropova, A.V. Kononov. pp. 53-57.

Syurin, V. N., 1998. Viral diseases of animals [Nodular dermatitis] / V.N Syurin, A.Ya. Samuylenko, B.V. Soloviev, N.V. Fomin. - M .: VNITIBP, 928p.

Tuppurainen, E. S. M., Lubinga, J. C., Stoltsz, W. H., Troskie, M., Carpenter, S. T., Coetzer, J. A. W., Venter, E. H., Oura, C. A. L., 2013. Mechanical transmission of lumpy skin disease virus by Rhipicephalus appendiculatus male ticks. Epidemiol. Infect. 141, 425-430.

Tuppurainen, E. S. M., Venter, E. H., Coetzer, J. A., 2005. The detection of lumpy skin disease virus in samples of experimentally infected cattle using different diagnostic techniques. Onderstepoort J. Vet. Res. 72(2), 153-164.

\section{How to cite this article:}

Kutumbetov, L. B., Myrzakhmetova, B. Sh., 2020. Studies on the forced adaptation of cells of testicles and kidneys of lambs and goats to continuous growth in vitro. Int. J. Curr. Res. Biosci. Plant Biol. 7(2), 22-29. doi: https://doi.org/10.20546/ijcrbp.2020.702.004 